\title{
1. Introduction: envisioning a successful steady-state economy
}

How do you envision a successful economy without continuous growth?

It helps to consider a prior question: how do you envision a successful Planet Earth without continuous growth? That is easy to envision because it exists! The Earth as a whole does not grow in physical dimensions. Yet it changes qualitatively, it evolves and develops. Total matter on Earth cycles, but does not grow. Energy from the sun flows through the earth coming in as low-entropy radiant energy, and exiting as high-entropy heat. But the solar flow is not growing. Nearly all life is powered by this entropic throughput of solar energy. There is birth and death, production and depreciation. New things evolve; old things go extinct. There is continual change. But the Earth is not growing.

The economy is a subsystem of the Earth. Imagine that the economy grows to encompass the entire earth. Then the economy would have to conform to the behavior mode of the Earth. Namely, it could no longer grow, and would have to live on a constant solar flow, approximating a steady state - an exceedingly large steady state to be sure, well beyond optimal scale. The economy would have taken over the management of the entire ecosystem - every amoeba, every molecule, and every photon would be allocated according to human purposes and priced accordingly. All 'externalities' would be internalized, and nothing could any longer be external to the all-encompassing economy. The information and management problem would be astronomical - central planning raised to the thousandth power! Long before such total takeover, the human economy and the civilization it supports would have collapsed.

To arrive at a vision that promises success we must discard some dead-end dreams - especially the just-mentioned dream of internalizing all biospheric relationships into the monetary accounts of the economy. To keep the economy manageable we must limit its physical scale relative to the containing ecosystem. The way to do that is to leave a large part of the ecosphere alone, to limit our absorption of it into the economic subsystem - to keep a large part of the earth ecosystem in natura - as a source for low-entropy matter/energy inputs and as a sink 
for high-entropy waste, and as a provider of life-support services. Laissez faire takes on a new meaning - it is the ecosystem that must be left alone to manage itself and evolve by its own rules, while the economy is carefully constrained in aggregate scale to stay within the limits imposed by the ecosystem. Environmental sources and sinks necessarily must be used to support life and production, but the rate of use must remain within the regenerative and absorptive capacities of the ecosystem. The metabolic throughput from nature cannot keep growing. Limiting the physical throughput to sustainable levels will, by lowering supply, effectively internalize the external costs of excessive scale. Resulting higher resource prices will improve the microeconomic efficiency of allocation.

Every encroachment of the economy into the ecosystem is a physical transformation of ecosystem into economy. Growth means less habitat for other species, with loss both of their instrumental value to the ecosystem, and the intrinsic value of their own sentient life. Clearly, in addition to a maximum scale of the economy relative to the ecosystem, there is also an optimal scale (much smaller), beyond which growth becomes uneconomic in the literal sense that it increases environmental and social costs faster than production benefits. We fail to recognize the uneconomic nature of growth beyond this point because we measure only production benefits and fail to measure environmental and social costs. We ignore the fact that 'illth' is a negative joint product with wealth. Examples of illth are everywhere, even if usually unmeasured in national accounts, and include: climate change from excess carbon in the atmosphere, radioactive wastes and risks of nuclear power, biodiversity loss, depleted mines, deforestation, eroded topsoil, dry wells, rivers, and aquifers, sea-level rise, the dead zone in the Gulf of Mexico, gyres of plastic trash in the oceans, the ozone hole, exhausting and dangerous labor, and the unrepayable debt from trying to push growth in the symbolic financial sector beyond what is possible in the real sector.

Growth all the way to the very limit of carrying capacity has an unrecognized political cost as well. Excess capacity is a necessary condition for freedom and democracy. Living very close to the carrying capacity limit, as on a submarine or spaceship, requires very strict discipline. On submarines and spaceships we have a captain with absolute authority, not a democracy. If we want democracy, we should not grow up to the limit of carrying capacity - better to leave some slack - some margin of tolerance for the errors that freedom entails.

We need a nongrowing economy that strives to maintain itself in a steady state at something like the optimum scale. How to do that? Basically it is as simple (and difficult) as going on a diet. Cut the 
matter-energy throughput to a sustainable level by cap-auction-trade and/or ecological tax reform (taxing resource throughput - especially fossil fuels - rather than value added by labor and capital). We should cap or tax fossil fuels first. Then redistribute auction or eco-tax revenues by cutting income taxes for all, but first and mainly for the poor. A policy of quantitative limits on throughput (cap-auction-trade) raises resource prices and induces resource-saving technologies. The quantitative cap will also block the erosion of resource savings as induced efficiency makes resources effectively cheaper (the Jevons effect). In addition, the auction will raise much revenue and make it possible to tax value added (labor and capital) less, because in effect we will have shifted the tax base to resource throughput. Value added is a good, so we should stop taxing it. Depletion and pollution are bads, so we should tax them.

Along with a physical diet, we need a serious monetary diet for the obese financial sector, specifically movement away from fractional reserve banking toward a system of 100 percent reserve requirements. This would end the private banks' alchemical privilege to create money out of nothing and lend it at interest. Every dollar loaned would then be a dollar that someone previously saved, restoring the classical balance between abstinence and investment. This balance was abandoned by the Keynesian-neoclassical synthesis after the Great Depression because it was thought to be a drag on growth, the new panacea. But in the new era of uneconomic growth the classical discipline regains its relevance. Investors must choose only the best projects, thereby improving the quality of growth while limiting its quantity. This idea of 100 percent reserve requirements on demand deposits was championed by the early Chicago School in the 1930s, as well as by Irving Fisher of Yale, and probably first proposed in 1926 by Frederick Soddy, Nobel Prize-winning chemist and underground economist. Also, a small 'Tobin tax' on all financial trades would reduce speculative and destabilizing short-term trading (including algorithm-based computer trading on fraction of a second price differences) and raise significant revenue.

What about population growth? In my lifetime the world population has tripled, and the populations of other 'dissipative structures' (cars, houses, livestock, cell phones, and so on) have vastly more than tripled. Limiting the populations of artifacts by capping the metabolic throughput (food supply) that sustains them seems a good policy. However, limiting food supply to humans is nature's harsh limit, Malthus' positive check. There is also Malthus' preventive check (celibacy and late marriage), and the more palatable neo-Malthusian preventive check of contraception. Contraceptives should be made easily available for voluntary use everywhere. More people are better than fewer, but not if all are alive at the 
same time. We should strive to maximize the cumulative number of people ever to live over time in a condition of sufficiency. That means no more people alive at the same time than could enjoy a per capita resource availability that is enough for a good (not luxurious) life, and sustainable for a long (not infinite) future. Exactly how many people at exactly what per capita standard would that be? We do not know, but we do know that it is not more people at a higher per capita consumption, and that is enough to get started in the right direction.

Even if we limit quantitative physical throughput (growth) it would still be possible to experience qualitative improvement (development), thanks to technological advance and to ethical improvement of our priorities. Some say that we should not limit growth itself, but only stop bad growth and encourage good growth. However, only if we limit total growth will we be forced to choose good growth over bad. And furthermore, we can also have too much 'good' growth, or as it is often called 'green growth'. There is a limit to how many trees we can plant as well as to how many cars we can make. Growth beyond optimal scale is uneconomic growth, and we should stop the folly of continuing it.

If you are an optimist regarding 'soft' technologies (for example, conservation, solar) please have the courage of your convictions and join in advocating these policies that will give incentive to the resource-saving technologies that you believe are within reach. You may be right - I hope you are. Let us find out. If you turn out to be wrong, there is really no downside, because it was still necessary to limit throughput and consequently the 'hard' resource-intensive technologies (for example, fossil fuel, nuclear) that are currently pushing uneconomic growth.

Our strategy so far has been to seek efficiency first in order to avoid frugality - to keep the throughput growing. But 'efficiency first' leads us to the Jevons paradox - we just consume more of the resources whose efficiency we have increased, thereby partially or even totally canceling the initial reduction in quantity of resource used. If we impose 'frugality first' (caps on basic resource throughput), then we will get 'efficiency second' as an induced adaptation to frugality, avoiding the Jevons paradox. Blocking the Jevons paradox is an advantage of the capauction-trade system over eco-taxes, although taxes have the advantage of being administratively simpler. Both will work.

Is this vision of a developing but nongrowing economy not more appealing and realistic than the deceptive dream of an economy based on continuous growth? Who, in the light of biophysical reality, can remain committed to the growth-forever vision? Apparently our decision-making elites can. They have figured out how to keep the dwindling extra benefits of growth for themselves, while 'sharing' the exploding extra 
costs with the poor, the future, and other species. The elite-owned media, the corporate-funded think tanks, and the kept economists of high academia, Wall Street, and the World Bank, all sing hymns to growth in perfect unison, deceiving average citizens, and perhaps themselves. Their commitment is not to maximize the cumulative number of people ever to live at a sufficient standard of consumption for a good life for all. Rather, it is to maximize the standard of resource consumption for a small minority of the present generation, and let the costs fall on the poor, the future, and other species.

Some of the elite do not realize the cost of their behavior and will change once they are made aware. Others, I suspect, are already quite aware and do not care. The former can be persuaded by argument; the latter require repentance and conversion - or revolution, as Marxists would argue. Probably this line of division in some way runs through each of us rather than only between us. Intellectual confusion is real and we need better understanding, but that is not the whole story. The elite may already understand that growth has become uneconomic. But they have adapted by learning how to keep the dwindling extra benefits of growth, while 'sharing' the rising extra costs.

Indeed why not, if we believe that Creation is just a purposeless happenstance, the random consequence of multiplying infinitesimal probabilities by an infinite number of trials, as taught by the reigning worldview of naturalism? I say Creation with a capital ' $C$ ' advisedly, certainly not in denial of the established facts of evolution, but rather in protest to the naturalistic metaphysics, widespread among the intelligentsia, that all is purposeless happenstance. It is hard to imagine, under such a vision, from where the elite, or anyone else, would get the inspiration to care for Creation, which of course naturalists would have to call by a different name, say, 'Randomdom'. Imagine calling on people to work hard and sacrifice to save 'Randomdom' - the blind result of atoms swirling in the void! Intellectual confusion is real, but the moral nihilism logically entailed by the naturalistic scientism uncritically accepted by so many, may be the bigger problem.

I am not able to solve this larger metaphysical and moral difficulty, least of all in a short article aimed only at explaining the idea of a steady-state economy. But it would be disingenuous to pretend that merely describing an idea will solve the problem that gave rise to it. So in closing I at least mention what seems to me the deeper issue, and note that we will consider it further in Part IV. 
Herman E. Daly - 9781783479979 Downloaded from PubFactory at 04/26/2023 01:43:13PM via free access 